
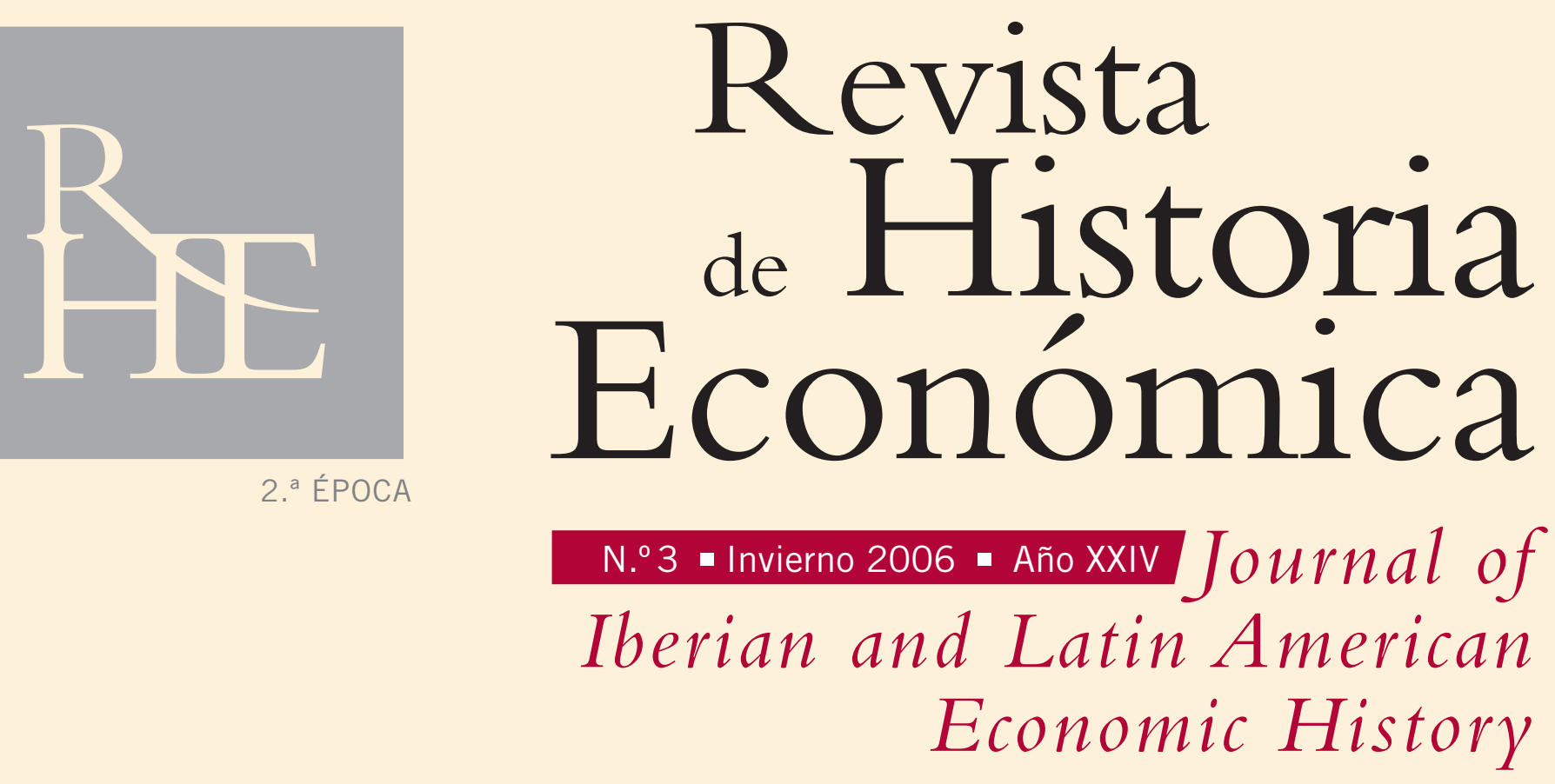

Jordi Domenech: Institutional change in industrial relations. Strike arbitration in Spain, 1880-1915 - Zephyr Frank: Stature in nineteenth-century Rio de Janeiro: preliminary evidence from prison records $\cdot$ Jorge Gelman y Daniel Santilli: Entre la eficiencia y la equidad. Los desafíos de la reforma fiscal en Buenos Aires. Primera mitad del siglo XIX - Roser Nicolau-Nos y Josep PujolAndreu: Variaciones regionales de los precios de consumo $y$ de las dietas en España, en los inicios de la transición demográfica - Clementina Ródenas y Segundo Bru: La convertibilidad de la peseta en el siglo XIX 

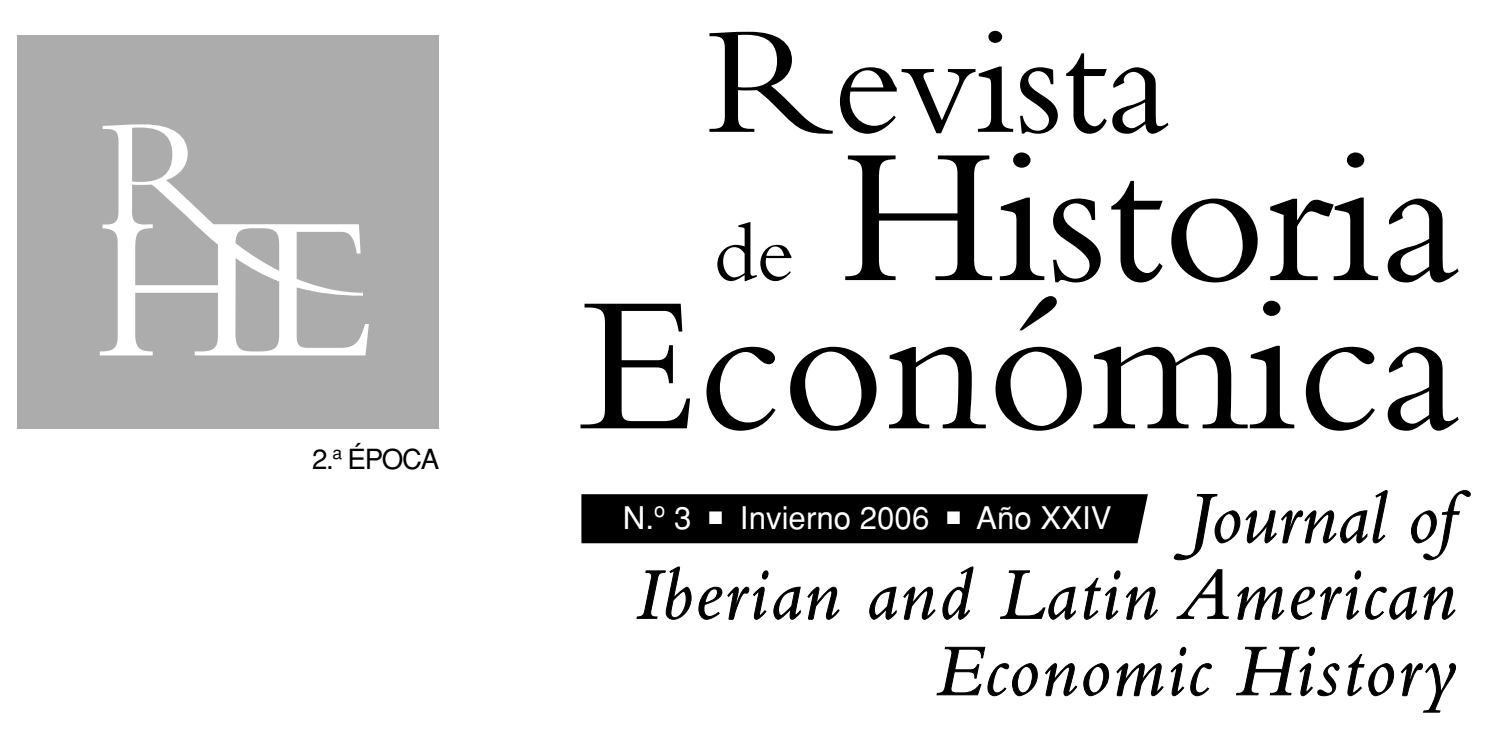
La correspondencia con la RHE-JILAEH debe dirigirse a rhe-jilaeh@uc3m.es

$\mathrm{O}$

al Director responsable Antonio TENA

(antonio.tena@uc3m.es)

Departamento Historia Económica

Universidad Carlos III de Madrid

c/ Madrid, 126 • 28903 Getafe

Madrid (España)

Tel. (34) 916249621

Suscripciones:

MARCIAL PONS

C/ San Sotero, 6 - 28037 Madrid (España)

Teléfono (34) 9130433 03. Fax (34) 913272367

revistas@marcialpons.es

\section{PRECIO 2007*}

\begin{tabular}{lc|c} 
& ESPAÑA & EXTRANJERO \\
Suscripción & $65 €$ & $90 €$ \\
\cline { 2 - 3 } Número suelto & $25 €$ & $35 €$ \\
\cline { 2 - 3 } Número extra & $45 €$ & $60 €$
\end{tabular}

* Iva no incluido

Distribuye:

MARCIAL PONS

Depósito legal: M. 29.208-1983

ISSN: 0212-6109

Impresión: ELECÉ, INDUSTRIA GRÁFICA, S. L. 


\section{SUMARIO}

\section{ARTÍcULOS}

Institutional change in industrial relations. Strike arbitration in Spain, 1880-1915

JORDI DOMENECH

Stature in nineteenth-century Rio de Janeiro: preliminary evidence from prison records 465 ZEPHYR FRANK

Entre la eficiencia y la equidad. Los desafíos de la reforma fiscal en Buenos Aires. Primera mitad del siglo XIX JORGE GELMAN y DANIEL SANTILLI

Variaciones regionales de los precios de consumo y de las dietas en España, en los inicios de la transición demográfica 521 ROSER NICOLAU-NOS y JOSEP PUJOL-ANDREU

La convertibilidad de la peseta en el siglo XIX 555 CLEMENTINA RÓDENAS y SEGUNDO BRU 


\section{ARTÍ́CULOS}

